\title{
A PRÁTICA DE PROFESSORES DA EDUCAÇÃO INFANTIL COMO AÇÃO PREVENTIVA DA VIOLÊNCIA SEXUAL DE CRIANÇAS
}

\author{
LA PRÁCTICA DEL PROFESOR DE EDUCACIÓN INFANTIL COMO ACCIÓN \\ PREVENTIVA DE LA VIOLENCIA SEXUAL INFANTIL
}

\author{
THE PRACTICE OF EARLY CHILDHOOD EDUCATION TEACHERS AS A \\ PREVENTIVE ACTION AGAINST SEXUAL VIOLENCE OF CHILDREN
}

\author{
Márcia Cristiane Ferreira MENDES ${ }^{1}$ \\ Anaisa Alves de MOURA ${ }^{2}$ \\ Maria da Paz Arruda ARAGÃO ${ }^{3}$
}

RESUMO: O presente artigo tem como objetivo refletir sobre a prática docente para o combate ao abuso e a exploração sexual de crianças, através das experiências obtidas no projeto de extensão e das ações pedagógicas ocorridas nos Centros de Educação Infantil públicas de Sobral - CE. Como abordagem metodológica, utilizamos a qualitativa. Para o aprofundamento teórico recorremos aos estudos de Caroline Arcari (2013), Rosemberg (1985), Bem e Wagner (2006), Werebe (1970), Ribeiro (1990), Maia e Ribeiro (2011), que discutem sobre Educação Sexual e violação de direito das Crianças e dos Adolescentes. Como resultado, apontamos a importância da formação de professores para a prevenção ao abuso sexual de crianças e da relevância de planejar suas ações pedagógicas nesta perspectiva, e proporcionar palestras para as famílias dos alunos como esclarecimento quanto à valorização familiar e à proteção e garantia de direito das crianças.

PALAVRAS-CHAVE: Educação sexual. Educação infantil. Prática pedagógica.

RESUMEN: Este artículo tiene como objetivo reflexionar sobre la práctica docente para combatir el abuso y explotación sexual infantil, a través de las experiencias obtenidas en el proyecto de extensión y las acciones pedagógicas que se desarrollaron en los Centros de Educación Infantil públicos de Sobral - CE. Como enfoque metodológico, utilizamos el enfoque cualitativo. Para la profundización teórica se utilizaron los estudios de la autora Caroline Arcari (2013), Rosemberg (1985), Bem y Wagner (2006), Werebe (1970), Ribeiro (1990), Maia y Ribeiro (2011), quienes discuten sobre Educación Sexual y violación de los derechos de la niñez y la adolescencia. Como resultado, señalamos la importancia de la formación docente para la prevención del abuso sexual infantil y la relevancia de planificar sus acciones

${ }^{1}$ Universidade Estadual do Ceará (UECE), Fortaleza - CE - Brasil. Doutoranda no Programa de Pós-graduação em Educação. Membro do Grupo de Pesquisa: Prática, Memória e Oralidade. ORCID: https://orcid.org/00000002-6219-7182. E-mail: marciacfmendes@gmail.com

${ }^{2}$ Universidade Lusófona de Humanidades e Tecnologias (ULHT), Lisboa - Portugal. Doutoranda em Ciências da Educação e Professora pesquisadora pela CAPES - Formação de Professores para a Educação Básica (PARFOR). ORCID: http://orcid.org/0000-0002-4878-089X. E-mail: anaisa1000@hotmail.com

${ }^{3}$ Universidade Lusófona de Humanidades e Tecnologias (ULHT), Lisboa - Portugal. Mestranda em Educação e Membro do programa PARFOR/CAPES/UVA como Professor Pesquisador II do Plano Nacional de Articulação e Formação de Professor da Educação Básica. ORCID: https://orcid.org./0000-0003- 2743-8777. E-mail: mparagao1@hotmail.com

RPGE- Revista on line de Política e Gestão Educacional, Araraquara, v. 24, n. esp. 3, p. 1900-1914, dez. 2020. e-ISSN:1519-9029 
pedagógicas en esta perspectiva, y brindar charlas a las familias de los estudiantes como explicación para la valorización familiar y la protección y garantía de derechos. de los niños.

PALABRAS CLAVE: Educación sexual. Educación infantil. Práctica pedagógica.

ABSTRACT: The objective of this article is to reflect on the teaching practice for combating the sexual abuse and exploitation of children through the experiences obtained in the extension project and the pedagogical actions that occurred in the Public Children Education Centers of Sobral - CE. As a methodological approach, we use qualitative. For the theoretical study, we used studies by Caroline Arcari (2013), Rosemberg (1985), Bem and Wagner (2006), Werebe (1970), Ribeiro (1990), Maia and Ribeiro (2011), who discuss sexual education and violation of the rights of children and adolescents. As a result, we point out the importance of teacher formation for the prevention of sexual abuse of children and the relevance of planning their pedagogical actions in this perspective, and to provide lectures for the families of the students as clarification regarding family valuation and the protection and guarantee of children's rights.

KEYWORDS: Sex education. Child education. Pedagogical practice.

\section{Introdução}

Ao realizarmos estudos sobre Educação Sexual no contexto escolar, especificamente na Educação Infantil, percebemos a importância desse conteúdo para a formação básica da criança e para a vida. Como afirmam Maia e Ribeiro (2011, p. 76), “[...] a formação do educador é fundamental. Cada vez mais se torna necessário que o professor receba formação para atuar em processos de educação sexual seja na sua formação acadêmica ou em projetos de educação continuada". Essa percepção motivou a concretização do projeto de extensão "UNINTA FAZ BONITO: prevenção da violência sexual de crianças e adolescentes", aplicado pelo Centro de Educação Infantil (CEI) no município de Sobral - CE. Esse projeto foi impulsionado pelas campanhas do Governo Federal para que os órgãos públicos e privados mobilizassem ações contra o abuso e exploração sexual de crianças e adolescentes no Brasil. Foi instituída nacionalmente a campanha "Faça Bonito" e, reforçada com o dia 18 de maio sendo "O Dia Nacional de Combate ao Abuso e à Exploração Sexual de Crianças e Adolescentes", pela lei $\mathrm{n}^{\circ}$ 9.970, de 17 de maio de 2000 .

A escolha da data deu-se por um crime de violência sexual cometido contra uma criança de oito anos, chamada Araceli, na cidade de Vitória - ES. A criança foi drogada, abusada sexualmente e assassinada, tendo seu rosto desfigurado por ácido, no dia 18 de maio de 1973. Esse acontecimento chocou a cidade de Vitória como toda a sociedade. Mesmo tendo grande repercussão na cidade, não levou à prisão dos três acusados, sendo estes de famílias 
tradicionais do estado do Espírito Santo. Esse acontecimento contribuiu para um novo olhar quanto à prevenção e à preservação da criança e da infância, em todos os seus aspectos.

A Educação Sexual nas escolas deveria ter relevância no contexto da prevenção ao abuso e exploração sexual de crianças e adolescentes, pois a partir do momento em que as crianças têm a percepção do seu corpo e quem poderá tocá-la criando um sentimento de segurança e autoestima poderá se proteger de possíveis abusadores. Por esse entendimento o presente estudo tem como objetivo refletir sobre a prática docente para o combate ao abuso e a exploração sexual de crianças, através das experiências obtidas no projeto de extensão e das ações pedagógicas ocorridas nos Centros de Educação Infantil públicas de Sobral - CE.

O interesse pelo estudo deu-se a partir das leituras das obras da autora Carolina Arcari e das reflexões oriundas do projeto de extensão "UNINTA FAZ BONITO: prevenção da violência sexual de crianças e adolescentes", com o objetivo de formar docentes para o combate ao abuso e à exploração sexual de crianças no município de Sobral - CE, através de ações com alunos e professores do Centro Universitário Inta-UNINTA, do curso de Pedagogia. A partir do projeto, foram proporcionadas formações aos docentes que estão inseridos na Educação Infantil de três escolas municipais de Sobral - CE, aprofundando seu conhecimento acerca das temáticas "Educação Sexual" e "Violência sexual de crianças", e intervenções pedagógicas com as crianças de 3 a 5 anos, de forma lúdica, valorizando seus sentimentos, autoestima, conhecimento de mundo e identidade.

A violência sexual ${ }^{4}$, segundo Ferreira e Azambuja (2011) é classificada em várias atividades: Abuso Sexual, Exploração Sexual, pedofilia, podendo ocorrer em ambientes extrafamiliares e intrafamiliares. $\mathrm{O}$ abuso sexual é definido quando um adulto se utiliza da inocência da criança e a ilude com ofertas de presentes ou ameaças para satisfazer-se sexualmente; a exploração sexual diferencia-se do abuso quando a criança é feita de mercadoria para remuneração em espécie para a criança ou por terceiros. A pedofilia trata-se de uma doença, um desvio sexual, que leva um indivíduo adulto a se sentir sexualmente atraído por crianças e adolescentes de forma compulsiva e obsessiva, podendo levar ao abuso sexual. Diferente do abusador casual, o pedófilo sente a necessidade de saciar sua compulsividade.

Ao elaborar o projeto de extensão, pensando na relevância da temática, algumas questões foram emergindo: Quais os aspectos relevantes para a sociedade quando é inserida a

${ }^{4}$ A violência Sexual pode ser definida como envolvimento da criança e adolescente, dependentes e imaturos quanto ao seu desenvolvimento, em atividades sexuais que eles não têm condições de compreender plenamente e para as quais são incapazes de dar consentimento, ou que violam as regras sociais e os papeis familiares (FERREIRA; AZAMBUJA, 2011, p. 17). 
educação sexual nas escolas? Como será a receptividade do projeto pelos gestores e pelo corpo docente das escolas? Mediante tais perguntas uma deu-se como norte para compor essa pesquisa: Como a temática "Educação Sexual" pode prevenir ou combater o abuso e a exploração sexual de crianças partindo das formações docentes nas escolas? Essa indagação contribuiu para dar continuidade ao estudo e refletir nas discussões e resultado.

Apontamos que a pesquisa permite-nos fazer reflexões acerca da nossa prática enquanto professor, enquanto educador e direcionar nossas ações à prevenção ao abuso de crianças, mas não só a prevenção, como também contribuir no seu desenvolvimento de forma integral, aprendendo no cotidiano a respeitar o outro, o espaço do outro, mesmo com suas limitações, o que daremos a seguir um norte metodológico e teórico relacionando as nossas reflexões quanto à Educação Sexual no Ensino Infantil.

\section{Metodologia}

Como abordagem metodológica utilizamos a qualitativa, através de estudos bibliográficos sobre a temática "Educação Sexual na Educação Infantil" e o relato de nossas experiências com a aplicação do projeto de extensão nos três Centros de Educação Infantil, instituições públicas de Sobral - CE. Os recursos utilizados no projeto e pelos professores das escolas para o desenvolvimento das atividades com os alunos foi o material paradidático: "Pipo e Fifi: prevenção de violência sexual na infância" (livro paradidático) de autoria de Caroline Arcari, publicado em 2013, por compreender a importância dos seus trabalhos direcionados às crianças, por serem materiais lúdicos que trabalham o "Toque do sim" e o "Toque do Não", sendo este um toque a ser incorporado no cotidiano dos alunos, favorecendo o respeito mútuo, os limites e a disciplina. Também fortalece a autoestima e os sentimentos das crianças, criando laços de confiança pelo professor ou por outra pessoa que configure essa referência de sentimento.

Com o estudo, buscamos compreender sobre a prática do professor como ação preventiva ao abuso sexual de crianças e sobre a relevância da temática, optando por realizar uma coleta de dados nas plataformas de acervos digitais, nos Periódicos da Coordenação de Aperfeiçoamento de Pessoal de Nível Superior (CAPES) e da Scientific Electronic Library Online - Scielo, buscando no assunto pelo descritor "Educação Infantil" e "Violência Sexual". Nos periódicos da Capes foram encontrados 582 trabalhos, ao refinar por artigos publicados nos dois últimos anos, somaram-se 77 artigos. Na Scielo, buscando o assunto pelo descritor 
"Educação Infantil" e "Violência Sexual", não foi encontrado nenhum artigo. O que apontamos é que se trata de reflexões relevantes acerca de um assunto complexo para a educação.

Dessa maneira, estando na condição de docentes do projeto, percebemos a importância da Educação Sexual como prática preventiva da violência sexual de crianças. Entendemos que a criança passa boa parte da sua vivência na escola e, em alguns momentos, podem apresentar mudanças comportamentais, tendo ligação a algum tipo de violência, no caso a violência sexual. Para a realização da observação foram escolhidos três Centros de Educação Infantil, da Rede Municipal de Sobral - CE, mediante a permissão oficializada e protocolada na Secretaria de Educação da cidade. Os CEI escolhidos tiveram como inclusão aquelas que estavam mais próximas ao centro da cidade. Optamos também por não identificar as escolas e os professores e mencioná-los de forma geral "professores" e "CEI", e evidenciar as percepções dos autores no momento das ações e fundamentar as discussões em relação à importância da prevenção ao abuso sexual de crianças baseados na prática do professor, como uma ação pedagógica.

\section{História da Educação Sexual no Brasil}

A educação sexual tem provocado discussões em relação a sua prática nas escolas, exatamente por ser uma temática que nem todos têm entendimento e por ser um assunto que, por muitos anos, era considerado constrangedor. O fato de não tocar no assunto em ambientes familiares e nas escolas era entendido como coerente, porque o não esclarecer não envolveria um aguçamento por outras curiosidades sexuais. Nesse entendimento, iremos traçar como veio desenvolvendo-se os estudos sobre a temática "Educação Sexual" ao longo da história e da necessidade da sua prática atual nas escolas. Cabe destacar que poucos autores falam da História da Educação Sexual no Brasil e, quando mencionam, trazem a referência do texto da autora Rosemberg (1985), ao qual faremos menção ao longo dessa reflexão.

A educação no Brasil, desde a consolidação dos sistemas educacionais de ensino, no século XIX, era regida pela igreja católica e, por ser uma educação religiosa, alguns conteúdos eram restritos, como a Educação Sexual. O que se entendia, tomando como base o evangelho sagrado, é que fomos criados a imagem e semelhança de Deus, então, não necessitaria outros esclarecimentos, apenas essas afirmações. De acordo com Rosemberg (1985):

A igreja católica constituiu um dos freios mais poderosos, até a década de 60 , para que a Educação Sexual formal penetrasse no sistema escolar brasileiro. Em primeiro lugar, por sua posição claramente repressiva em matéria de sexo; em segundo lugar, pela posição de destaque que ocupou na educação nacional, através da manutenção e da ferrenha defesa de sua rede de ensino. 
A partir da década de 60, começaram a ocorrer transformações culturais, políticas e sociais, dando início à implantação de programas de educação sexual em algumas escolas do país. No ambiente educacional, a falta de informação, ao invés de inibir a curiosidade das crianças que estão na transição para a adolescência, provocava mais curiosidade. Essa inibição era praticada pelos adultos, mas, se analisarmos, a consciência da sua sexualidade era tida como um pensamento pecaminoso, inclusive pelos seminaristas e padres que faziam o voto de castidade. A punição para proibir esses pensamentos era permitida pela educação religiosa, assim como pela a familiar, a dor disciplinar era relacionada à prática pedagógica. Conforme Rosemberg (1985, p. 12), "nesse ambiente escolar, o discurso formal sobre a sexualidade ou era negado ou era usado como pretexto para desencadear comportamentos punitivos".

$\mathrm{Na}$ estrutura das escolas católicas, algumas alterações, com o tempo, foram sendo permitidas, pois, no modelo patriarcal, não eram aceitas as escolas mistas (a educação dos meninos e meninas na mesma sala e no mesmo ambiente escolar). As trocas de convivência entre as crianças de outros gêneros, não se firmavam nas escolas, mas nos ambientes familiares vigiados e nas igrejas. Então, modifica-se o entendimento dos sistemas de ensino e permitemse as escolas mistas como favorecedora da aprendizagem e da troca de conhecimento. $\mathrm{O}$ ensino laico começa a ser exigido nos planos educacionais, desestruturando em algumas cidades as escolas religiosas. Rosemberg (1985, p. 12) diz que "No plano educacional também são introduzidas modificações: escolas católicas passam a ser mistas ou se fecham".

A educação organizada pela igreja católica, podemos dizer, foi o entrave para pensar na "Educação Sexual", pois não permitia que os conteúdos fossem transmitidos aos alunos de forma didática, o que propiciou iniciativas isoladas, como São Paulo, Rio de Janeiro e Belo Horizonte. Essa temática era tomada como atribuição da área de Saúde.

Assim, ainda sendo um período autoritário regido por um poder conservador, na década de 1970, é censurado e proibido que essa prática seja realizada nas escolas, foi vetada a inclusão obrigatória do Ensino de "Educação Sexual” nos currículos de $1^{\circ}$ e $2^{\circ}$ graus do ensino primário e secundário. Como afirma Rosemberg (1985, p. 12):

Estas experiências da rede pública deixaram de existir em 1970, após um pronunciamento da Comissão Nacional de Moral e Civismo dando parecer contrário ao projeto de lei da deputada Júlia Steinbruch (MDB-RJ) que, em 1968, propunha a inclusão obrigatória de Educação Sexual nos Currículos de $1^{\circ}$ e $2^{\circ}$ graus (então denominados de primário e secundário). Essa rejeição e teor do parecer, sobre o qual voltaremos adiante, não foram um fato isolado, mas decorreram de uma série de atos autoritários implantados no país. 
A proibição inibiu ações isoladas de escolas públicas mediante o decreto e pelos pareceres que foram proferidos à deputada Júlia Steinbruch. Mas, em escolas experimentais essa prática foi mantida e sendo vigiada pelas autoridades governamentais, até mesmo por se tratar de um período marcado pela violência aos direitos humanos pela ditadura militar. Segundo Werebe (1970, p. 26), "no âmbito escolar, afora iniciativas isoladas feitas no anonimato, as primeiras realizações práticas - e que constituíram experiências sistemáticas foram quase todas promovidas no contexto de ensaios de renovação pedagógica". Ainda Segundo Rosemberg (1985, p. 12):

As autoridades educacionais, no período, faziam marcar sua presença vigilante como guardiãs da moral dos alunos. As escolas experimentais eram mantidas sob vigilância. Um processo que ocorreu em São Paulo, em 1973, ilustra essa disposição de vigiar e punir. O pivô do processo foi o livro infantojuvenil. O caneco de prata, de autoria de João Carlos Marinho.

A compreensão sobre a Educação Sexual, cabe apontar, muda mediante a interpretação que a sociedade faz em torno do tema. Na década de 1970, o que se entendia sobre Educação Sexual era apenas como uma forma de prevenção à gravidez e os aspectos biológicos. Essa temática foi entendida como atribuição do professor de filosofia, dentro do programa de Educação e Saúde, mas não integrada à Educação Infantil. Como afirma Ribeiro (1990, p. 2), "Os primeiros trabalhos de educação sexual eram voltados basicamente para o prisma biológico. Tanto que a aula de ciências, tranquilamente, "dava conta" do que se acreditava ser um trabalho de educação sexual".

Em 11 de agosto de 1971, surgiu a lei de número 5.692. Pela qual foram criadas disciplinas de programas à saúde na escola. Em seguida, surgiram vários livros sobre a saúde e a educação sexual. A volta da discussão sobre a "Educação Sexual" deu-se em 1978, mas na mesma perspectiva da preservação familiar, sendo ainda proibida nas escolas, como afirma Rosemberg (1985):

Publicamente a educação sexual nas escolas voltou a ser mencionada em junho de 1978 quando um dos programas de TV de maior audiência no país, que vai ao ar domingo à noite, apresentou uma reportagem sobre Educação Sexual na Escola. O ministro da Educação - (Euro Brandão) entrevistado é categórico. Declara-se contra a Educação Sexual na escola, mas favorável a uma educação para constituição da família (sic) (Visão, agosto de 1978).

Nesse período também começa a idealização para a redemocratização do país. Neste sentido, as propostas sobre a Educação Sexual afloraram. Os jovens adaptavam-se a uma nova 
fase na qual tinham acesso a todo tipo de informação sobre a educação sexual, e acostumavamse a novas regras e valores que estavam sendo instituídos.

Com a democratização e uma nova forma de governo, veio o entendimento da garantia de direto da criança em todos os seus aspectos, em 1990 foi promulgado o Estatuto da Criança e do Adolescente (ECA), tendo em seu artigo $4^{\circ}$ os direitos basilares deste público, entre eles, a educação, a profissionalização e a cultura da criança, sendo os responsáveis por fazer valer esta norma a família, a sociedade e o Estado. Dentre as recomendações, o direito a educação é prioridade. Em 1996, a orientação sexual teve seus direitos oficializados, quando foi aprovada a Lei de Diretrizes e Bases e o estabelecimento dos Parâmetros Curriculares Nacionais, segundo os quais a orientação sexual deveria ser trabalhada em todas as disciplinas de forma transversal.

Segundo Maia e Ribeiro (2011), na década de 1990, a intervenção na escola visando atuar com questões sexuais era denominada Orientação Sexual, termo, aliás, que acabou sendo adotado pelos Parâmetros Curriculares Nacionais. Surgiu, porém, uma divergência de opinião acerca do termo mais adequado a ser utilizado: não havia unanimidade na aceitação da Orientação Sexual e muitos autores preferiam utilizar educação sexual. Na década de 2010 surgiu um termo adicional, que é a Educação para a Sexualidade, que igualmente não encontrou a unanimidade desejada. A terminologia mais aceita é a Educação Sexual. Maia e Ribeiro (2011, p. 77) apontam que:

Divergências à parte, já que dificilmente contribuem para o fortalecimento da educação sexual enquanto ciência da educação e campo de intervenção pedagógica, optamos por adotar educação sexual como o processo pedagógico que visa uma formação específica e intencional sobre sexualidade, e o que dela é decorrente: comportamentos e atitudes, ética e valores, práticas e concepções.

A Base Nacional Comum Curricular (BNCC) refere-se à educação sexual como algo a ser abordado nos anos finais do Ensino Fundamental, isso relacionado à reprodução e à sexualidade humana, assuntos de grande interesse e relevância social nessa faixa etária, assim como são relevantes, também, o conhecimento das condições de saúde, do saneamento básico, da qualidade do ar e das condições nutricionais da população brasileira. O que destacamos é a importância da prevenção ao abuso desde o ensino infantil, pois também é nessa fase que são relatados muitos casos de abusos no Brasil. O material didático lúdico adequado, que valoriza o respeito, o outro, a autoestima, o conhecimento de mundo, contribui para que as crianças contem às pessoas de confiança o que está acontecendo ao seu redor. Por isso que, nas observações realizadas nas escolas, estudos, relatos de profissionais da saúde e da educação que trabalharam a prevenção ao abuso desde a Educação Infantil, permitiram detectar possíveis 
abusadores ou indicar possíveis mudanças comportamentais provocando um olhar mais direcionado às crianças.

\section{Educação Sexual na Educação Infantil: Reflexão Docente}

Essa reflexão originou-se a partir das ações do projeto de extensão e da percepção da importância do compromisso docente quanto a formação para a prevenção da violência sexual de crianças. As estatísticas de abusos contra as crianças têm aumentado consideravelmente, o que, diante da realidade brasileira, faz com que seja relevante o entendimento do educador quanto à temática, possibilitando o uso de meios didáticos para as percepções de mudanças comportamentais da criança e de marcas físicas que poderão apresentar. Segundo Arcari (2013), dados disponibilizados pelo Instituto Cores, 1 a cada 5 crianças são abusadas, 1 a cada 10 casos de abuso são relatados. Dos casos que ocorrem, $87 \%$ acontecem no seio familiar ou são amigos próximos da família. Segundo Lessa e Mayor (2019), apesar da concepção social de família ser construída em torno do amor, do cuidado e da proteção, a tendência que vem sendo observada é uma maior incidência de casos de Abuso Sexual Infantil (ASI) ocorrendo dentro do seio familiar. As crianças têm sido vítimas desses abusos onde deveriam ser protegidas, e as escolas, nesse sentido, podem se constituir em ação preventiva e combater essas violações, além de permitirem que as crianças vivam o que lhes é de direito. As ações nas escolas, mediante a ação do projeto, proporcionaram uma percepção dos seus corpos, o reconhecimento de sua autoestima e autonomia, assim pode compreender a importância de manter seus sentimentos e corpos seguros.

Segundo Lessa e Mayor (2019), no boletim do Ministério da Saúde, no Brasil, no período de 2011 a 2017, foram notificados 184.524 casos de violência sexual, sendo 58.037 contra crianças e 83.068 contra adolescentes. Os dados explicitados revelam um aumento de $64,6 \%$ nas notificações de violência sexual contra crianças e $83,2 \%$ contra adolescentes, desde 2011 (BRASIL, 2018). As estatísticas levantadas demonstram como a violência sexual infantil atingiu níveis epidemiológicos, sendo extremamente alarmante o fato de que esses dados não refletem o número real de Abuso Sexual Infantil (ASI) no Brasil, e sim, apenas os casos notificados. Estima-se que são denunciados $2 \%$ dos casos de abuso sexual infantil dentro da família e $6 \%$ dos casos de abuso sexual fora da família. Isso significa dizer que a maioria dos casos não estão contabilizados nas estatísticas.

Segundo Arcari (2015), as formas de prevenção minimizam os índices apontados, é possível nomear três tipos de prevenção (primária, secundária e terciária), sendo a mais 
utilizada, por ser considerada econômica e eficiente, a prevenção primária. Esta que tem como o objetivo eliminar todos os tipos de maus tratos, sejam culturais, sociais ou ambientais. Com o apoio da implementação de políticas sociais básicas, promovem ações educativas a toda a população. Segundo o Guia Escolar (2015), o passo inicial da prevenção primária é ter materiais suficientes para ajudar a escola a informar a comunidade sobre a violência sexual contra as crianças e adolescentes.

O propósito do projeto "UNINTA FAZ BONITO: prevenção da violência sexual de crianças e adolescentes", é exatamente contribuir para diminuição desses dados, mesmo sabendo que é uma ação pequena diante de uma notificação tão alta, mas é preciso que cada instituição ou pessoa deem a sua colaboração à sociedade. Nesse entendimento, com primeiro passo, foram selecionados três CEI para uma formação, utilizando conceitos sobre "Violação Sexual”, “Tipos de abusos", "Exploração Sexual”, "Possíveis abusadores”, situações nas quais as crianças podem sofrer a violência sexual, os tipos de comportamento que podem apresentar quando passam por uma situação de violação. Esse contato inicial possibilitou que os professores estivessem mais abertos à temática como também a ampliar seus conhecimentos, visto que para alguns isso ainda era um tabu a ser tocado e trabalhado didaticamente nas escolas. Com o planejamento, as escolas puderam organizar as ações, pois o projeto tinha um prazo de dois meses para ser concretizado, mas caso as escolas viessem a ter uma necessidade de dar continuidade ao projeto, estariam livres para pensarem nas próximas ações e torná-las contínuas. Com o uso do Livro "Pipo e Fifi”, como material paradidático, tornou-se acessível concretizar as ações do planejamento individual e coletivo do professor.

A formação para os professores sobre a temática torna-se importante, pois como a criança passa boa parte da vida na escola, este pode apresentar mudanças comportamentais, ocasionadas por situações vivenciadas fora do ambiente escolar, e o professor pode identificar alterações de hábito da criança, como a agressividade ou o recolhimento. Esse processo também é evidenciado por Lessa e Mayor (2019) que apoiam a necessidade da capacitação dos profissionais da educação, sobretudo, professores que possuem contato direto com os alunos para sua atuação como agentes de prevenção do ASI.

Segundo Arcari (2015), é importante que o professor compreenda as fases de desenvolvimento da criança para desenvolver as atividades de prevenção. Com isso a mesma autora relaciona comportamento psicossexual típicos de crianças de 0 a 5 anos no seu material “Guia para pais e educadores: Como trabalhar o livro em espaços educativos". Nesse sentido, tendo a participação de como a criança desenvolve-se ao longo dos anos, a autora ainda aponta conhecimentos necessários para o seu processo pedagógico: 
Já deve aprender a nomear todas as partes do corpo;

Devem saber quais são as pessoas autorizadas a auxiliá-la com a higiene (mãe, avó, pai, cuidadores da creche);

Deve saber informações básicas sobre partes íntimas; como dizer NÃO, como buscar ajuda caso seja tocada de forma abusiva;

Deve saber informações básicas sobre o corpo, de onde vêm os bebês, diferenças do corpo do adulto e da criança (ARCARI, 2015).

As professoras inseriram a contação de história, do livro "Pipo e Fifi", de maneira bem divertida, mas, mesmo com a introdução do tema, algumas professoras restringiam-se ou ficavam constrangidas ao ensinar a criança sobre "Educação Sexual". Um ponto positivo, que é preciso mencionar, é que mesmo reconhecendo essa preocupação com a temática, por não saber como as famílias iriam receber a informação em casa pelas crianças, as CEI investiram na formação e na aplicação do projeto nas salas de aulas da Educação Infantil por reconhecer que deveriam prevenir o abuso sexual de crianças. Eram tabus que precisariam ser quebrados pelos próprios professores por reconhecer seus valores familiares, suas crianças e por estarem ainda presos pela falta de informação.

Assim, após as formações pedagógicas com os docentes e percebendo a relevância da temática, as atividades foram dando continuidade, sendo aplicadas semanalmente, a princípio com a contação da história do livro "Pipo e Fifi". Quando estávamos nas salas observando o desenvolvimento das atividades, percebemos que os personagens já eram de conhecimento das crianças, reconheciam as atividades impressas, as colagens, os desenhos para pintar e ao perguntarmos quem eram nos desenhos, respondiam prontamente.

Com a contação de histórias e as ilustrações dos personagens do livro, "Pipo e Fifi", facilitou a compreensão dos alunos pelos desenhos lúdicos, sem levar para outra dimensão ou aguçar outro tipo de curiosidade sexual, compreenderiam seu corpo, fortalecendo seus sentimentos e sua identidade e visão de mundo, da realidade que está a sua volta. Após a inserção dos personagens, foram utilizados os toques "sim" e "não", como uma forma de compreender o que é permitido ou não. Dessa maneira, as atividades basearam-se no respeito aos colegas e aos professores. O importante do estabelecer o toque do "Não" e do "Sim" é que estes sejam incorporados ao cotidiano das crianças como uma limitação e delimitação do seu espaço e dos seus corpos.

Às crianças, em seu desenvolvimento, é imprescindível que tenham no seu cotidiano palavras que coloquem limites. O "Não" é uma delas, sendo primordial para enfrentar as dificuldades e barreiras que são apresentados ao longo da vida e que serão mais aceitáveis, sem causar comportamentos depressivos ou agressivos por não aceitarem os "Nãos" da vida. 
Segundo La Taille (1999), o termo limite é associado à obediência, ao respeito, à retidão moral e à cidadania. Sugere ainda que o limite colocado favorece a maturidade do indivíduo.

No estabelecimento de limites, a família e a escola têm papel importante. Segundo Bem e Wagner (2006), a família, por ser a primeira instituição social com a qual a criança tem contato, é a sede da socialização. A escola, por sua vez, além de ser uma instituição responsável pelo desenvolvimento do conhecimento formal, também desempenha papel importante no estabelecimento dos limites infantis.

Os índices de violência contra a mulher vêm crescendo no Brasil e os limites impostos pelo toque do "Não" e do "Sim" contribuem para que homens e mulheres respeitem uns aos outros. Que os homens aprendam a lidar com a negativa e as frustrações da vida e passem a valorizar o ser humano sem recorrer à agressão. Que tratem as mulheres com respeito e dignidade e não como objeto, conforme o modelo patriarcal, onde as mulheres viviam à sombra dos homens e sofriam várias violências e eram silenciadas, pois a sociedade não as via com bons olhos ao denunciarem seus parceiros e achavam que se foram violentadas é porque foram subversivas aos seus maridos ou que mereceram ser punidas, através da violência.

Conforme Schraiber (2007), a violência vivida pelas mulheres é hoje questão de saúde. Sua forma mais comum é aquela perpetrada por parceiros íntimos. Organizações internacionais (Organização Mundial da Saúde - OMS, Organização Panamericana da Saúde, Banco Mundial) e de profissionais de saúde (Associação Médica Americana) têm divulgado elevadas prevalências da violência por parceiros íntimos. Além de alta magnitude, esses episódios de violência mostram caráter muitas vezes grave e reiterado, expressando a desigualdade nas relações de gênero. As repercussões estendem-se à saúde física, psicológica e reprodutiva das mulheres e podem permanecer mesmo após o término da violência. Por isso, em relação ao desenvolvimento das crianças, elevando sua autoestima, sua autonomia e conhecimento do mundo, contribui para que estas mantenham seus corpos protegidos.

\section{Considerações finais}

O estudo em questão apresenta relevância por se tratar de uma temática que tem contribuído quanto à prevenção ao abuso de crianças e adolescentes, que estão inseridos nas CEI e por entender que esses sujeitos passam boa parte da vida no ambiente escolar, podendo apresentar mudanças comportamentais. No projeto "UNINTA FAZ BONITO: prevenção da violência sexual de crianças e adolescentes", o foco maior era inquietar os educadores quanto a sua formação sobre a temática em Educação Sexual e na contribuição de prevenir o abuso 
sexual de crianças. Entendemos que a infância corresponde à fase inicial e que a ação preventiva deve vir desde essa fase.

Esse estudo tem-nos mostrado, enquanto docentes e discentes, que essa ação deve continuar e se ampliar para outras CEI e outras modalidades de educação, e ser tomada como ação das Secretarias de Educação das cidades brasileiras, favorecendo a construção de uma sociedade humanizadora, respeitando a dignidade e a saúde mental e emocional humana. A prevenção ao abuso deve ser tomada não só por uma ação individual, mas também, coletiva.

Em relação às escolas, em sua maioria, o primeiro impacto foi de estranhamento, por haver certo receio sobre o tema "Educação Sexual", mas após a explanação do projeto e os recursos didáticos, foram percebendo que o conteúdo era importante e que os materiais disponíveis correspondiam à fase de desenvolvimento das crianças, respeitando a ludicidade e a criatividade. Também nas formações, foi mencionado o que iria ser trabalhado nas salas de aula para o fortalecimento emocional, a percepção da identidade e o conhecimento do corpo e do mundo. Após o projeto e os conceitos compreendidos, alguns hábitos foram sendo aprimorados e incorporados para uma boa limitação de espaço e respeito mútuo como uma referência para a criança.

Outro fator de aprimoramento em relação ao projeto é que, mesmo com as percepções dos discentes e dos docentes referentes à importância da prevenção ao abuso de crianças como ação preventiva nas escolas, é a necessidade de incluir as famílias, principalmente, porque casos de abusos sexuais ocorrem frequentemente em ambientes familiares. Os autores dos abusos que geralmente acontecem são pessoas próximas, podendo ser padrasto ou madrasta, amigos e parentes próximos. O que propomos em ações futuras ampliar as atividades do projeto e atender à demanda familiar de alunos que estão matriculados nas escolas.

\section{REFERÊNCIAS}

ARCARI, C. Pipo e fifi. São Paulo: Instituto Cores, 2013.

ARCARI, C. Caderno de atividades. São Paulo: Instituto Cores, 2013.

ARCARI, C. Guia para pais e educadores: como trabalhar o livro em espaços educativos. São Paulo: Cores, 2015.

BARROSO, L. M.; BRUSCHINI, M. C. A. Educação sexual: debate aberto. Petrópolis, RJ: Vozes, 1986. 
BEM, L.; WAGNER, A. Reflexões sobre a construção da parentalidade e o uso de estratégias educativas em famílias de baixo nível socioeconômico. Psicologia em Estudo, Maringá, v. 11, n. 1, p. 63-71. 2006. DOI: https://doi.org/10.1590/S1413-73722006000100008

BRASIL. Lei n. 9.394, de 20 de dezembro de 1996. Lei de Diretrizes e Bases da Educação Nacional. Diário Oficial da União: Seção 1, Brasília, DF, n. 248, p. 27833, 23 dez. 1996.

BRASIL. Base Nacional Comum Curricular. Disponível em:

http://basenacionalcomum.mec.gov.br/abase/\#fundamental/lingua-portuguesa-no-ensinofundamental-anos-finais-praticas-de-linguagem-objetos-de-conhecimento-e-habilidades. Acesso em: 14 out. 2020.

BRASIL. Lei n. 8.069, de 13 de Julho de 1990. Dispõe sobre o Estatuto da Criança e do Adolescente, e dá outras providências. Diário Oficial da União: Seção 1, Brasília, DF, p. 13563,16 jul. 1990.

FERREIRA, M. H. M.; AZAMBUJA, M. R. F. Violência sexual contra crianças e adolescentes. Porto Alegre: Artmed, 2011.

LA TAILLE, Y. Limites: três dimensões educacionais. São Paulo: Ática,1999.

LESSA, C. B.; MAYOR, A. S. A Dificuldade na Promoção de Medidas Preventivas Contra o Abuso Sexual Infantil nas Escolas. Persp. Online: hum \& sociais aplicada, Campos dos Goytacazes, v. 25, n. 9, p. 61-78, 2019.

MAIA, A. C. B.; RIBEIRO, P. R. M. Educação sexual: princípios para ação. Doxa: Revista Paulista de Psicologia e Educação, Araraquara, v. 15, n. 1, p. 75-84, 2011. ISSN 1413-2060. Disponível em:

https://www.academia.edu/12736279/Educa\%C3\%A7\%C3\%A3o_Sexual_princ\%C3\%ADpio s_para_a\%C3\%A7\%C3\%A3o. Acesso em: 10 out. 2020.

RIBEIRO, M. Educação sexual e metodologia. Reprolatina institucional. São Paulo: EPU, 1990. Disponível em:

http://www.reprolatina.institucional.ws/site/respositorio/materiais_apoio/textos_de_apoio/Edu cacao_Sexual.pdf. Acesso em: 9 out. 2020.

ROSEMBERG, F. Educação sexual na escola. Caderno de Pesquisa, São Paulo, n. 53, p. 1119, maio 1985. Disponível em: https://dialnet.unirioja.es/descarga/articulo/6135829.pdf.

Acesso em: 9 out. 2020.

SCHRAIBER, L. B. L. et al. Prevalência da violência contra a mulher por parceiro íntimo em regiões do Brasil. Rev Saúde Pública, São Paulo, v. 41, n. 5, p. 797-807, 2007. ISSN 15188787. 2007. DOI: https://doi.org/10.1590/S0034-89102007000500014

WEREBE, M. J. G. Implantação da Educação Sexual no Brasil. Cadernos de Pesquisa, n. 26, p. 21-34, 1970. Fundação Carlos Chagas. 1970. Disponível em:

http://www.ijsn.es.gov.br/ConteudoDigital/20180709_cadernosdepesquisa_n.26_set1978_p.2 1_34_.pdf. Acesso em: 9 out. 2020. 


\section{Como referenciar este artigo}

MENDES, M. C. F.; MOURA, A. A.; ARAGÃO, M. P. A. A prática de professores da educação infantil como ação preventiva da violência sexual de crianças. Revista on line de Política e Gestão Educacional, Araraquara, v. 24, n. esp. 3, p. 1900-1914, dez. 2020. e-ISSN:1519-9029. DOI: https://doi.org/10.22633/rpge.v24iesp3.14468

Submetido em: 10/08/2020

Revisões requeridas: $20 / 10 / 2020$

Aprovado em: 05/11/2020

Publicado em: 30/11/2020 